FINANÇAS

\title{
A \\ irracionalidade das bolhas
}

radicional mente, a teoria econômica pressupõe que os indi-
víduos seguem os princípios da racionalidade e tomam de-
cisões levando sempreem conta o conceito de maximização do valor. Contudo, cabe questionar se os investidores se comportam de forma perfeitamente racional. Este artigo examina um dos exemplos mais marcantes de uma possível irracionalidade dos mercados financeiros: a ocorrência das chamadas bolhas especulativas.

por César Nazareno Caselani FGV-EAESP

Freqüentemente, os agentes econômicos são vistos como indivíduos racionais. A racionalidade presume pessoas dotadas de um modelo de tomada de decisão bem definido, que permite julgar a melhor dentre várias alternativas de escolha, levando-se em conta conceitos como utilidade e maximização de valor. Em outras palavras, a decisão de um agente racional só é efetuada após a ponderação dos custos e benefícios associados às diversas alternativas.

I gualmente, quando se trata de avaliar o mercado financeiro como um todo, muitas pessoas tendem a acreditar que ele funciona de forma perfeitamente coerente e racional, refletindo as tendências futuras da economia. Entretanto, cabe 
questionar se os indivíduos e os mercados são de fato perfeitamente racionais. Um dos exemplos mais marcantes deuma possível irracionalidade dos mercados financeiros é a ocorrência das chamadas bolhas especulativas.

Uma bolha especulativa ocorre quando os preços dos ativos negociados em um dado mercado sofrem uma forte valorização ou desvalorização sem que tal movimento reflita, de forma razoável, o "valor justo" desses ativos. Ou seja, as bolhas especulativas envolvem, em maior ou menor grau, um movimento artificial de preços.

Este artigo questiona a idéia de que é possível confiar nos mercados como representantes fiéis das premissas de otimização da racionalidade econômica. Ele é uma continuidade e uma resposta a dois outros artigos publicados na RAE-executivo: no primeiro deles - "A racionalidade em cheque", de Mauro Halfeld e Fábio de Freitas Leitão Torres (v. 1, n. 1) - foram apresentados os fundamentos das finanças comportamentais; no segundo - "Tempestade explicada", de Pedro Fachada(v. 1, n. 2) - foi feita uma discussão estritamente econômica das bolhas especulativas. Aqui, são utilizados os pressupostos das finanças comportamentais para analisar especificamente um importante fenômeno do mercado financeiro: 0 surgimento e o rompimento das bolhas especulativas.

correta, o fato de o índice da Bolsa de Valores de São Paulo ter experimentado um incremento de $24 \%$ ao longo de 2003 (até 12 de junho) deve-se ao fato do Ibovespa incorporar todas as informações às quais o mercado teve acesso nesse período. Entreas informações positivas que proporcionaram uma al ta do Ibovespa no período estão a redução do risco Brasil, 0 aumento do superávit da bal ança comercial ea possibilidade de avanços nas diversas reformas em curso previdenciária, tributária e do judiciário.

Se os mercados fossem perfeitamente eficientes, não haveria espaço para a ocorrência de anomalias como as bolhas especulativas. Portanto, uma vez que as evidências apontam para o fato de que o mercado não se comporta de forma eficiente, então énecessária uma outra abordagem, quevenha a complementar as lacunas deixadas pela teoria da eficiência. A abordagem alternativa surgiu com força na década de 1990 e tornou-se conhecida como finanças comportamentais. Os estudos nesse campo têm como objetivo contestar o comportamento estritamente racional dos agentes econômicos.

Em um artigo entitulado "Bubbles, human judgment, and expert opinion" (publicado no Financial Analysts) ournal, em 2002), Robert Shiller, um dos principais autores em Finanças Comportamentais, discute o componente de irracionalidade por trás das bolhas especulativas. Segundo 0 autor, tanto os investidores em geral como os profissionais experientes no mercado financeiro estão sujeitos a tomar decisões que não seguem o modelo econômico de racionalidade.

Eficiência questionada. Do ponto de vista econômico, a teoria dos mercados financei ros e a percepção dos indivíduos estão fortemente baseadas no conceito de eficiência de mercado. Mercado eficiente é aquele no qual todas as informações disponíveis se encontram refletidas nos preços dos ativos negociados. Acreditar na eficiência do mercado equivale a crer queo mercado se encontra em estado permanente de equilíbrio, refletindo deforma incontestável os fundamentos sobre o valor dos ativos.

Supondo que a teoria da eficiência do mercado esteja
Autores como Richard Thaler denominam comportamento quase-racional aquele que não segue total mente os princípios da racional idade. 0 resultado do comportamento quase-racional é a possibilidade de alimentação de bolhas especulativas, mesmo por parte dos profissionais do mercado financeiro que deveriam ser capazes de identificá-las.

A teoria do feedback. ParaShiller, o modelo de feedback é a razão para a existência de bolhas especulativas. Uma alta especulativa de preços, ao gerar ganhos substanciais para al- 
guns investidores, acaba por chamar a atenção do mercado. Por sua vez, o entusiasmo do mercado aumenta a demanda por ativos em alta. Finalmente, o aumento da demanda faz crescer ainda mais o tamanho da bolha.

0 mecanismo de feedback acaba por gerar um otimismo (ou pessimismo) exacerbado, o que amplifica os movimentos de alta (ou baixa) dos preços. Além disso, elimina parcial ou completamentea racionalidadena decisão de investimento por parte dos agentes do mercado, sejam eles especialistas ou não. Se o mecanismo de feedback não for contido, chegase ao ponto no qual os preços não podem mais ser sustentados, o que causa o estouro da bolha.

0 exemplo mais recente de bolha especulativa em escala mundial foi o que ocorreu com as empresas de tecnologia, especialmente as "ponto.com". As Figuras 1 e 2 mostram os desempenhos dos índices I bovespa e $\mathrm{N}$ asdaq, respectivamente. A razão para a queda mais acentuada do índice $\mathrm{N}$ asdaq foi a grande participação das ações de tecnologia em sua carteira, quando comparado com - Ibovespa. Os níveis dos índices em junho de 2003 mostram que, após o estouro da boIha, os mercados continuam distantes dos patamares máximos de val orização atingidos em março de 2000.

Padrões e estereótipos. M uitas pessoas ainda se perguntam como foi possível que os analistas financeiros do mundo inteiro tenham errado tão grosseiramente em suas previsões a respeito do valor das ações de tecnologia. Conforme Shiller, uma das respostas para isso está na "heurística representativa", o fenômeno que leva osindivíduos a tomarem decisões tendo em mente padrões ou estereótipos preestabelecidos, sem levar em conta as probabilidades reais de ocorrência de um determinado fenômeno.

No caso das previsões com relação às ações, a utilização da heurística representativa leva as pessoas a acreditarem na existência de padrões de alta ou baixa no mercado acionário, ainda que tais padrões se apresentem como raros ou com baixapossibilidade de ocorrência. Foi o que aconteceu no caso das ações de tecnologia. A euforia do mercado com relação àquilo que pareciaser uma revolução tecnológica sem precedentes gravou na mente dos investidores a sensação de que a elevação no preço das ações não teria limites. Mesmo que isso fosse improvável do ponto de vista dos fundamentos econômicos, a euforia dominou a razão.

O Brasil e o dólar. Outro exemplo de forte movimento especulativo digno de nota foi o que afetou a cotação do dólar no Brasil em 2002. À medida que se consolidava a vitória de Lula nas eleições, o dólar disparava. A Figura 3 destaca a cotação média do dólar comercial entre janeiro de 2002 e junho de 2003. No início do ano passado, o dólar comercial era cotado a aproximadamente $\mathrm{R} \$ 2,30$. Em pouco menos de sete meses, a moeda havia superado $R \$ 3,00$, até que, em

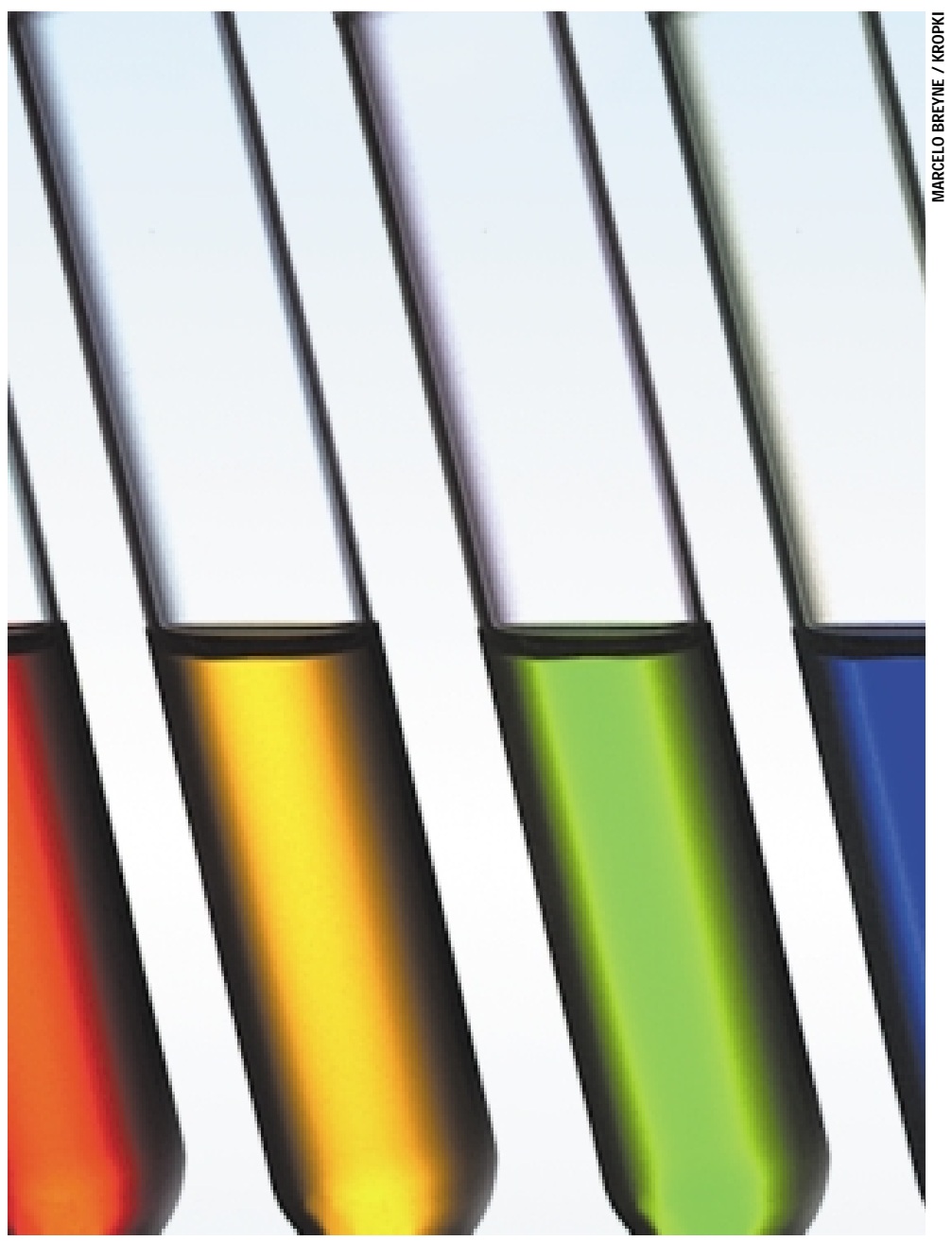


outubro, a cotação média ficou próxima de $R \$ 4,00$. Com 0 resultado das urnas e o início do novo governo, o dólar recuou progressivamente, até atingir um patamar em torno de $\mathrm{R} \$ 2,86$ em meados de junho de 2003.

A dúvida que pode surgir com relação ao movimento do dólar é se ele configurou ou não a existência de uma bolha especulativa. Inicialmente, é importante separar 0 conceito de especulação da ocorrência de bolhas no mercado. A essência dos movimentos do mercado e de seus diversos agentes residena existência da especulação. Por exemplo, quando um investidor decide transferir seu dinheiro de um fundo de ações para um fundo de renda fixa, ele pode estar especulando com a alta nas taxas de juros. É a

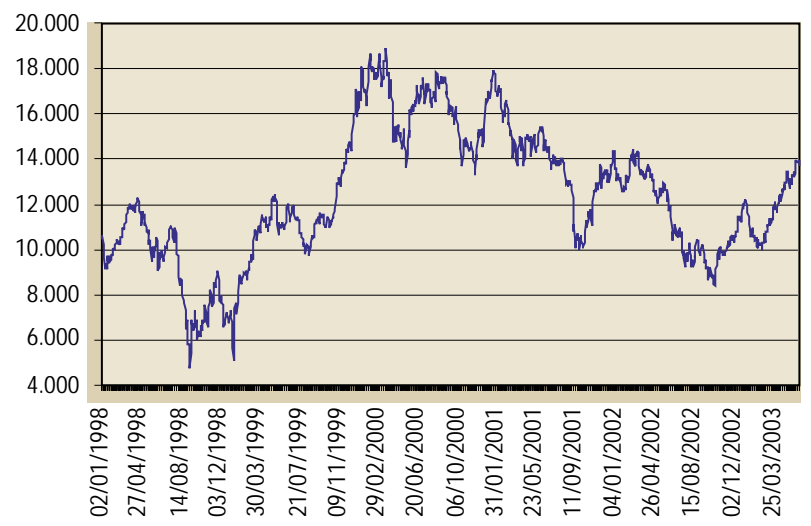

Figura 1: Desempenho do Ibovespa em pontos

Fonte: Ipeadata

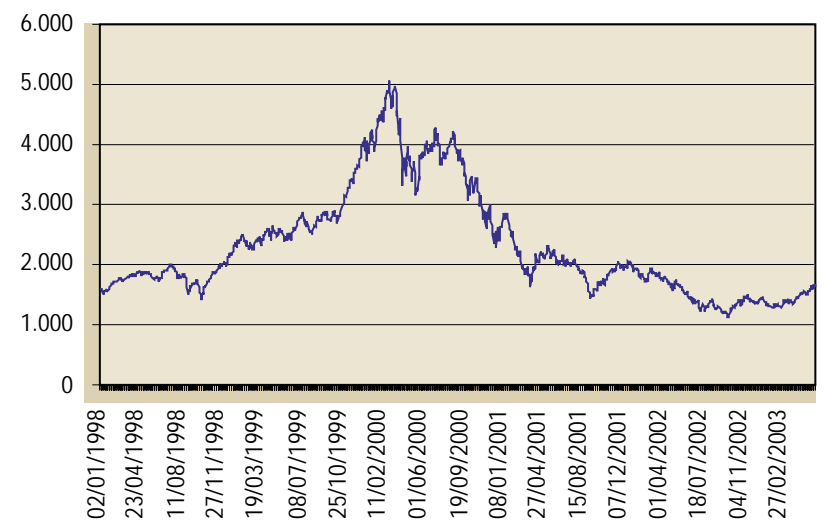

Figura 2: Desempenho do índice Nasdaq em pontos

Fonte: Ipeadata existência de especulação entre os agentes econômicos que faz com que ocorram movimentos de compra e venda de ativos no mercado. Um movimento especulativo exacerbado leva à formação de bolhas. Entretanto, uma vez que a especulação é uma característica inerente aos mercados, não deve ser vista sempre como algo irracional e que leva à formação de bolhas.

Voltando à oscilação do dólar no período eleitoral, naquele instante 0 mercado entendia que a troca de governo trazia consigo um ambiente de instabilidade econômica. Primeiro, existia o temor de que algumas posições radicais da esquerda brasileira contaminassem a política econômica do governo. Segundo, o discurso moderado do candidato Lula era visto por al guns agentes do mercado como sujeito a profundas alterações após a posse.

A incerteza com relação ao que viria em 2003 levou a uma maior demanda por ativos com características de reserva de valor, como o dólar. Com isso, é possível que alguns investidores tenham gerado uma apreciação exagerada da moeda. Contudo, se o novo governo tivesse implementado uma política completamente distinta do governo anterior (o que não aconteceu), hoje dificilmente alguém entenderia a elevação do dólar como uma bolha. Assim, infelizmente, é difícil separar o grau de especulação "razoável" daquele que leva à existência de bolhas.

Envolvimento emocional. Além da heurística representativa, outro fator que pode afetar o julgamento de especialistas e investidores é a facilidade com que eles se envol-

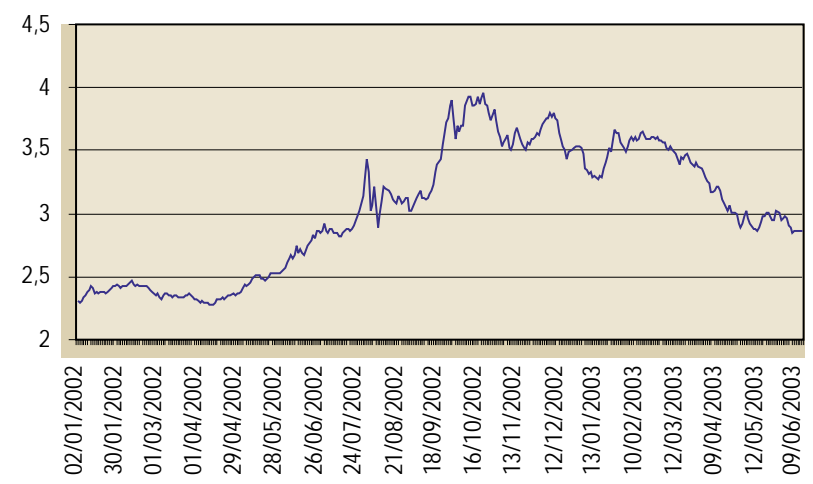

Figura 3: Evolução da taxa de câmbio

Fonte: Ipeadata 
vem emocional mente com suas estratégias de investimentos. Por exemplo, à medida que um profissional do mercado obtém sucesso com sua estratégia, a sensação de que o bom desempenho no passado garantirá o sucesso futuro é ampliada. Não édifícil ver profissionais de mercado vangloriando-se de sua capacidade acima da média em realizar projeções competentes com relação ao cenário econômico futuro. Nesses casos, tal excesso de confiança irá afastar o profissional de análises baseadas nos fundamentos, tornando-o refém de uma estratégia supostamente imbatível.

Essa postura facilita a crença de que um movimento persistente dos mercados seja uma confirmação das projeções do analista, e não uma bolha. Enquanto as previsões se mostrarem corretas, o profissional tenderá a relacionar seu bom desempenho à própria competência. Caso os fatos não confirmem o que era esperado pelo analista, então a justificativa será falta de sorte ou até mesmo má-fé por parte dos demais agentes do mercado.

"Efeito manada". 0 arsenal de dados eferramentas quantitativas à disposição de um analista financeiro costuma ser bastante expressivo. Contudo, tomar uma decisão de investimento não é uma tarefa fácil. Além dos elementos quantitativos, a decisão do especialista costuma levar em conta elementos qualitativos. E estes envolvem o consenso do grupo de profissionais de mercado, o padrão de prudência exigido pelos clientes e a participação da mídia na divulgação de notícias. Dificilmente um especialista irá decidir isoladamente sobre a estratégia adequada de investimento. Antes, ele buscará ouvir a "voz do mercado", em busca de um elemento de consenso que sustente sua decisão.

Dessa forma, o julgamento individual do analista necessita da sanção de seus pares para ser implementado. Devese levar em conta que as pessoas buscam sempre manter 0 status dentro do grupo ao qual pertencem, e isso é possível quando se segue a opinião de consenso da categoria profissional. 0 problema reside exatamente no risco incorrido pelo gestor financeiro que, ao seguir o mercado, presume que os formadores do consenso tenham avaliado cuidadosamente os fundamentos antes de tomar uma decisão. $\mathrm{Na}$ inexistência desse cuidado, o "efeito manada", gerado por aqueles que apenas seguem os formadores de opinião, poderá criar uma bolha especulativa.
Identificando bolhas especulativas. É importante destacar que a existência das bolhas especulativas é uma evidência empírica de que a teoria da eficiência do mercado oferece espaço para críticas. Dessa forma, decisões de investidores que levam à formação dessas bolhas devem ser entendidas em vista das variáveis qualitativas e quantitativas inerentes aos processos decisórios, conforme apresentado acima.

Porém, a grande incógnita que permanece diz respeito à identificação das bolhas. É difícil separar a especulação fundamentada daquela geradora de bolhas. Entretanto, a despeito dessa dificuldade, é importante ter em mente algumas regras: primeiro, a freqüência com a qual determinado fato é comentado não significa necessariamente uma tendência de mercado; segundo, os fundamentos econômicos são válidos, mas isso não significa que o mercado irá refletir tais fundamentos o tempo todo; e, terceiro, é importante verificar se os profissionais de mercado estão realizando uma análise baseada em estudos aprofundados ou simplesmente replicando o senso comum.

Seguir essas regras não é garantia de sucesso nos investimentos, mas evita uma exposição excessiva às conseqüências de bolhas especulativas.

César Nazareno Caselani

Prof. do Departamento de Contabilidade, Finanças e Controle da FGV-EAESP

Doutorando em Administração de Empresas na FGV-EAESP

E-mail: ccaselani@fgvsp.br 